\title{
Bilateral Acanthamoeba ulcer in a user of disposable soft contact lenses: a tragic incident or a consequence of the aggressive policy of soft contact lens trading?
}

\author{
Úlcera bilateral por Acanthamoeba em usuária de lentes de contato gelatinosas \\ descartáveis: um incidente trágico ou uma conseqüência da política agressiva \\ de venda de lentes de contato gelatinosas?
}

Sidney Júlio de Faria e Sousa ${ }^{1}$

Vanderson Glerian Dias ${ }^{2}$

Luís Antonio Gorla Marcomini ${ }^{3}$

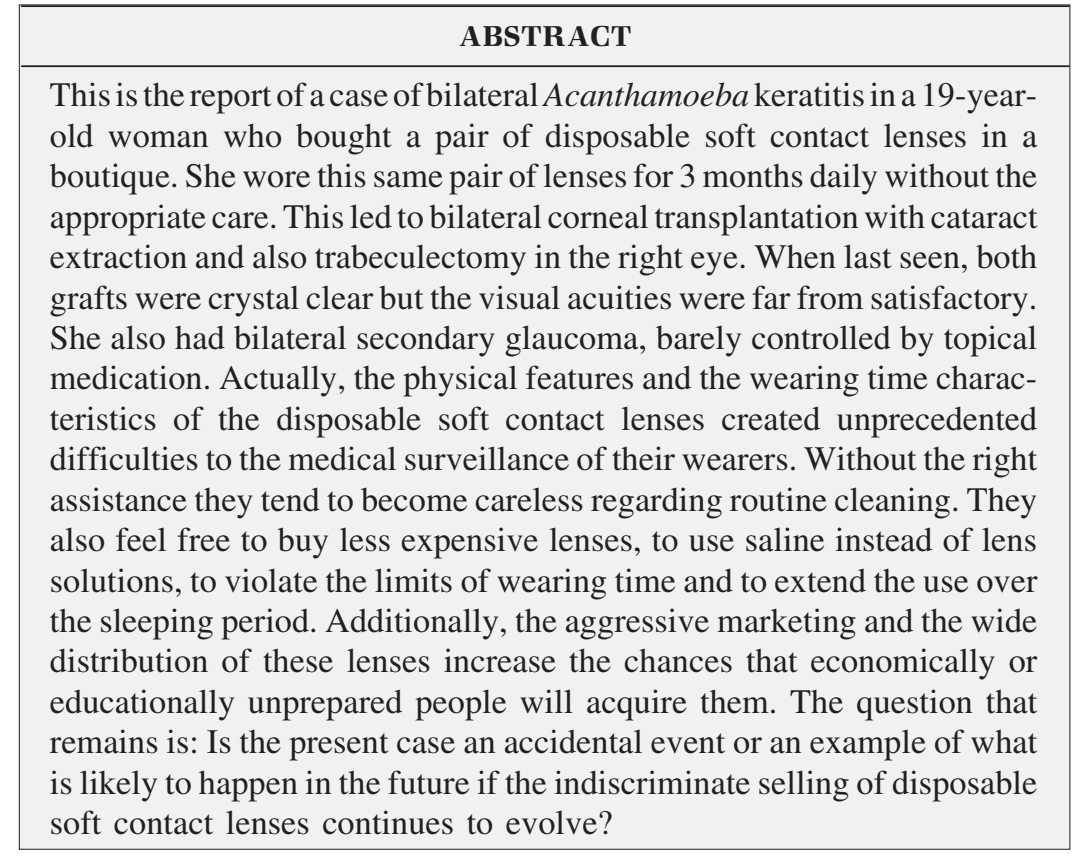

Keywords: Eye infections; Acanthamoeba keratitis; Corneal ulcer; Contact lenses, hydrophilic; Human; Female; Adult; Case reports [Publication type]

\section{INTRODUCTION}

Faculho realizado no Departamento de Oftalmologia da dade de São Paulo - USP - Ribeirão Preto (SP) - Brasil.

Associate Professor of the Department of Ophthalmology, Faculdade de Medicina de Ribeirão Preto, University of São Paulo - USP - Ribeirão Preto (SP) - Brazil.

Medical Assistant of the Department of Ophthalmology, Faculdade de Medicina da USP - Ribeirão Preto (SP) Brazil.

${ }^{3}$ Medical Assistant of the Department of Ophthalmology, Faculdade de Medicina da USP - Ribeirão Preto (SP) Brazil

Correspondence to: Sidney Júlio Faria e Sousa. Departamento de Oftalmologia da Faculdade de Medicina de Ribeirão Preto - Campus Universitário. Av. Bandeirantes, 3.900 - Ribeirão Preto (SP) - CEP 14049-900

E-mail: sidneyjulio@terra.com.br

Recebido para publicação em 26.05.2007

Última versão recebida em 27.09.2007

Aprovação em 20.02.2008

\section{CASE REPORT}

In June 12, 2005 a 19-year-old woman from Porto Velho, Brazil, sought treatment at the Eye Clinic of our School of Medicine. She had acquired 
bilateral corneal ulcer after wearing for three months the same pair of monthly disposable soft contact lenses (Acuvue ${ }^{\circledR}$; Johnson \& Johnson, USA). The patient bought them in a boutique. She learned the handling and care of these lenses inside the car of the dealer. At first, she used the right lens solution but when it finished she changed to saline solution. For eight months she used various eyedrops whose name she did not know. On the first visit at our service she was using $0.3 \%$ gatifloxacin ophthalmic solution $\left(Z^{2 y m a r}{ }^{\circledR}\right.$; Allergan, Brazil) and 1\% prednisolone acetate eyedrops, four times daily each.

The visual acuity in both eyes was 0.01 . Slit lamp examination demonstrated a bilateral deep disciform infiltrate affecting the center and the intermediate portion of the cornea. These two regions were divided by a deep annular stromal thinning (Figure 1). The anterior chambers were formed but the irises were barely visible. The eyes were fairly hyperemic and the eyelids moderately edematous. Symptoms included pain, photophobia and tearing, although not intense. The anxiety of the patient was extreme.

The history and clinical examination suggested the diagnosis of Acanthamoeba keratitis, which was later confirmed by laboratory analysis. Because of the extent of corneal involvement the decision was to begin with clinical treatment and to postpone corneal transplantation. After corneal scrapings were obtained for diagnostic purposes, therapy was initiated with $0.02 \%$ polyhexamethyl biguanide and $0.1 \%$ propamidine isethionate (Brolene; Aventis, Kent, UK) eyedrops hourly along with $200 \mathrm{mg}$ ketoconazole in tablet form, two times daily. This therapy was tapered off over a period of four months.

Three days later, pain and vision became worse in the left eye. The cornea of this eye became thinner, almost exposing the Descemet membrane. To avoid perforation a corneal transplantation was scheduled. Meanwhile, temporary therapeutic soft contact lenses were fitted in both eyes. On June 22, the corneal transplantation was canceled because of a massive left orbital hemorrhage during peribulbar anesthesia. On June 25 , the surgery was finally performed under general anesthesia. The surgical procedure was difficult owing to the rise of intraocular pressure (IOP) during surgery. The inflamed iris, which partially adhered to the lens and to the peripheral cornea, caused many episodes of bleeding. In addition, when an attempt was made to disengage peripheral synechiae a huge

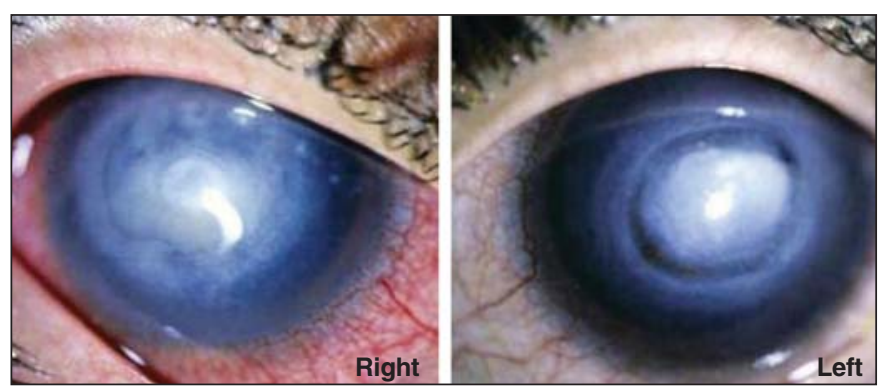

Figure 1 - Bilateral Acanthamoeba keratitis tear occurred in the temporal iris insertion, creating almost a double pupil. The diameters of the recipient bed and graft were 8.5 and $9 \mathrm{~mm}$, respectively.

On July 5, the patient had a spontaneous corneal perforation of the right eye accompanied by intense pain. On July 8, we carried out a penetrating corneal transplantation in this eye under general anesthesia. The corneal melting became evident during surgery. The iris and the lens were totally covered by a dense and adherent fibrin membrane. The lens also showed visible signs of cataract. The diameters of the recipient bed and graft were 7.75 and $8.25 \mathrm{~mm}$, respectively.

On August 26, the left eye underwent a new intervention to correct herniations of the iris through the corneal surgical wound at 7 and 11 o'clock, respectively. On August 27, the IOP of this eye was found to be $30 \mathrm{mmHg}$. A regimen of $0.2 \%$ brimonidine tartrate and $0.5 \%$ timolol maleate combination eyedrops (Combigan ${ }^{\circledR}$; Allergan, Brazil) three times daily was instituted along with $250 \mathrm{mg}$ acetazolamide in tablet form twice a day.

On September 8, because the IOP of both eyes was $30 \mathrm{mmHg}$, oral acetazolamide was administered every 6 hours. Combigan $^{\circledR}$ eyedrops were also introduced in the right eye. Steroid drops, initiated after the corneal transplantations and oral fluoxetine prescribed by the psychiatrist, were discontinued.

On February 14, the patient was submitted to phacoemulsification, lens implantation and trabeculectomy in the right eye. On March 6, the right and left IOP were 20 and $18 \mathrm{mmHg}$, respectively, even though the patient was using bilaterally Combigan ${ }^{\circledR}$ eyedrops every 8 hours and $0.004 \%$ travaprost (Travatan ${ }^{\circledR}$; Alcon, Brazil) at night. The corneas were crystal clear with no signs or symptoms of infection. The visual acuity of both eyes with eyeglasses was 0.2 . The patient had to return to her home town and was lost to follow-up.

\section{DISCUSSION}

Our Institution receives mainly low-income patients who, as a rule, do not wear contact lenses. Consequently, the majority of our cases of corneal ulcers are not related to these lenses. In fact, until 2003 only 5\% of the cases recorded as having infectious ulcers were associated with contact lenses. Among them, only one case had a diagnosis of Acanthamoe$b a$. However, in the last two years eight new cases of Acanthamoeba keratitis were recorded in our Service, all of them involving wearers of disposable soft contact lenses. Table 1 describes their characteristics.

The present case is number 6 in table 1 . This case has various peculiarities: (1) this was the only patient who could not afford to buy the lens solution on a regular basis. All other cases consisted of middle-class people in a position to follow rigorously the protocol of contact lens wear and care. With the exception of cases 2 and 6, all had free access to doctors, without further expenses; (2) this was the only patient whose lenses were fitted by unauthorized personnel and in an inap- 
432 Bilateral Acanthamoeba ulcer in a user of disposable soft contact lenses: a tragic incident or a consequence of the aggressive policy of soft contact lens trading?

\begin{tabular}{|c|c|c|c|c|c|c|c|}
\hline Case & $\begin{array}{c}\text { Lens } \\
\text { material }\end{array}$ & $\begin{array}{c}\text { First } \\
\text { purchase }\end{array}$ & $\begin{array}{l}\text { Subsequent } \\
\text { purchases }\end{array}$ & $\begin{array}{c}\text { Care } \\
\text { solution }\end{array}$ & $\begin{array}{l}\text { Use of } \\
\text { saline }\end{array}$ & $\begin{array}{l}\text { Wearing time } \\
\text { (days) }\end{array}$ & $\begin{array}{c}\text { Wearing } \\
\text { during sleep }\end{array}$ \\
\hline 1 & Etafilcon A & Physician & Optical shop & Renu* & Regularly & 45 & Sporadically \\
\hline 2 & Etafilcon A & Optical shop & Optical shop & Opti-free $^{+}$ & Regularly & 30 & No \\
\hline 3 & Etafilcon A & Physician & Optical shop & Opti-free $^{+}$ & Regularly & 50 & Sporadically \\
\hline 4 & Etafilcon A & Physician & Optical shop & Renu* & Regularly & 60 & Never \\
\hline 5 & Methafilcon A & Physician & Physician & Complete $^{\circ}$ & Never & 30 & Never \\
\hline 6 & Etafilcon A & Boutique & - & Renu* & Once & 90 & Never \\
\hline 7 & Etafilcon A & Physician & Optical shop & Renu* & Never & 30 & Always \\
\hline 8 & Etafilcon A & Physician & Physician & Renu* & Never & 30 & Never \\
\hline
\end{tabular}

propriate place; (3) finally this was the patient who most violated the scheduled period of lens wear.

On the other hand, there are interesting similarities between this case and the others in table 1: (1) the lenses of the present case, like all the other lenses listed, belong to the category of ionic, high water content, monthly disposable soft contact lenses. This is probably due to the substantial preponderance of these lenses on the Brazilian market. However, one should not forget the fact that the structural features of the disposable lenses probably play a role in the etiology of Acanthamoeba keratitis ${ }^{(9-10)}$. The high hydration, the ionic nature and the edge design facilitate the adhesion of Acanthamoeba to their surfaces; (2) with the exception of cases 5 and 8, all wearers were buying the lenses in optical shops at the time their keratitis started. Paradoxically, most of them had the first pair fitted in medical offices. In fact, this seems to be a distinctive behavioral pattern of the wearers of disposable lenses, at least in our country: the first pair is fitted by an ophthalmologist. Next, the wearers abandon medical supervision and start buying the lenses in optical shops. Then, they change the brand of their lenses according to immediate convenience, without expert guidance. The brands with the most aggressive advertisement, the largest delivery network and the better prices become the most popular, independently of true merit. This is, probably, the main explanation for the vast prevalence of etafilcon A lenses in table 1.

Until 1993, when the first disposable contact lenses were introduced in our country, the absolute majority of the fittings were done by ophthalmologists. Trained opticians, following medical prescription, fitted only a small percentage of lenses in optical shops. These lenses were replaced every one or two years. Each replacement was accompanied by a meticulous eye examination by the ophthalmologist going over the contact lens care protocol. There was reciprocity between the patient and the fitter: the former was faithful to the latter and the latter was committed to the former. The disadvantage of this system was that the control of the contact lens market belonged to the ophthalmologist. Being protected from the competitive drives of the free market, the price of the fittings was thought to be relatively unaffordable by a considerable part of the population.
This scenario changed completely with the advent of disposable lenses. The following features of these lenses probably contributed to this change: 1) they are easier to fit; 2) their replacement is not regularly monitored by the fitter; 3) their acquisition characterizes better the purchase of a commodity than the purchase of a service; 4) the wearers can buy them without medical surveillance.

Since conventional soft contact lenses were originally made with three different curvatures they required keratometry and slit lamp analysis of the lens movements for fitting. Disposable lenses practically eliminated these procedures. This encouraged the wearers to try different lenses by themselves without expert assistance. Additionally, the high rate of replacements, inherent to these lenses, rendered impractical the systematic surveillance of their substitution. Therefore, the concept that the fitter should monitor all contact lens replacements was insidiously undermined.

Our legislation does not allow ophthalmologists to sell optical aids. The classical justification of these professionals for charging the contact lenses is that the charge is for the fit and not for the product. With the advent of disposable lenses this excuse vanished. For example, when selling a box with three pairs of lenses, even if the patient is examined in each transaction, the fitter will be acting in only one of every three replacements; two of these replacements will be charged without any medical service. In practice, the problem is even greater. Once the doctors accepts the idea that not all replacements must be monitored they easily go one step further: they compromise medical surveillance. When this happens, the patient can no longer identify differences between acquiring lenses in medical offices, optical shops or pharmacies. In summary, the features and the protocol of use of disposable lenses conspire against the idea that the wearers must be under medical surveillance.

Also working against medical surveillance is the trading policy of some big contact lens suppliers based on a two-step strategy: first, they persuade the ophthalmologists of a target region to make their patients switch from conventional to disposable lenses. Once this objective is fulfilled, the marketing focus is transferred from the medical offices to the optical shops and pharmacies. With larger number of sale spots and 
competitive prices, these places easily push the ophthalmologists away from the soft contact lens market. Concomitantly, the soft lens wearers move away from medical assistance.

Our theory is that with the decline of medical surveillance due to the advent of disposable lenses, the wearers tend to be careless regarding routine care. They also feel free to buy less expensive lenses, to use saline instead of lens solutions, to violate the scheduled wearing time and to extend wear to sleeping time. Table 1 shows all of these events. In fact what this table shows is the general behavior of our contact lens wearers, independent of the presence of any complication. Apart from statistical analysis, it is impressive to observe that the only cases in which the wearers strictly followed the protocol were those monitored by ophthalmologists since the beginning (cases 5 and 8 ).

It seems unquestionable that disposable lenses increased the opportunity for people to wear contact lenses. One question arises here: is the present report the mere result of a tragic incident or is it an example of what is likely to happen in the future if the selling of disposable soft contact lenses continues to reach persons economically or educationally unprepared to wear them?

\section{RESUMO}

Este é o relato de uma paciente do sexo feminino, de 19 anos, com ceratite bilateral por Acanthamoeba, devido ao uso de lentes de contato descartáveis, adquiridas em uma butique. Fez uso do mesmo par de lentes durante três meses, sem os cuidados adequados. Foi submetida a transplante penetrante de córnea e facectomia bilateral, além de trabeculectomia no olho direito. Quando vista pela última vez, os enxertos estavam transparentes, mas a visão de ambos os olhos não era satisfatória. Ela também apresentava glaucoma secundário bilateral, controlado precariamente com medicação tópica. Ocorre que, as características físicas e o regime de uso das lentes de contato gelatinosas descartáveis criam dificuldades adicionais para a vigilância médica dos seus usuários. Sem a assis- tência correta, eles relaxam com a rotina de limpeza, compram lentes mais baratas, usam soro fisiológico ao invés das soluções adequadas, violam os limites de uso e dormem com as mesmas. Além disso, o "marketing" agressivo e a ampla distribuição dessas lentes aumentam as chances de que pessoas, não preparadas econômica e educacionalmente, venham ter acesso às mesmas. A pergunta que fica é: Seria o presente caso um evento acidental ou um exemplo do que pode acontecer no futuro caso as lentes de contato descartáveis continuem sendo vendidas indiscriminadamente?

Descritores: Infecções oculares; Ceratite por Acanthamoeba; Úlcera da córnea; Lentes de contato hidrofílicas; Humanos; Feminino; Adulto; Relatos de casos [Tipo de publicação]

\section{REFERENCES}

1. Nosé W, Sato EH, Freitas D, Ribeiro MP, Foronda AS, Kwitko S, et al. Úlcera de córnea por Acanthamoeba: quatro primeiros casos no Brasil. Arq Bras Oftalmol. 1988;51(6):223-6.

2. Bocaccio F, Kwitko S, Boelter MC, Marinho D, Rymer S, Alves LS, et al. Ceratite por Acanthamoeba: relato de casos no Rio Grande do Sul. Arq Bras Oftalmol. 1997;60(3):268-74.

3. Driebe WT Jr. Present status of contact lens-induced corneal infections. Ophthalmol Clin North Am. 2003;16(3):485-94.

4. Seal DV. Acanthamoeba keratitis update - incidence, molecular epidemiology and new drugs for treatment. Eye. 2003;1(8):893-905.

5. López L, de Fernando S, Gaztelurrutia L, Vilar B, Pérez-Irezábal J, Barrón J. [Keratitis caused by Acanthamoeba spp.: presentation of 10 cases]. Enferm Infecc Microbiolol Clin. 2000;18(5):229-33. Spanish.

6. Obeid WN, Araújo R, Vieira LA, Machado MA. Ceratite bilateral por Acanthamoeba - relato de caso. Arq Bras Oftalmol. 2003;66(6):876-80.

7. Rama P, Matuska M, Viganó M, Spinelli A, Paganoni G, Brancato R. Bilateral Acanthamoeba keratitis with late recurrence of infection in a corneal graft: a case report. Eur J Ophthalmol. 2003;13(3):311-4.

8. Chen WL, Wu CY, Hu FR, Wang IJ. Therapeutic penetrating keratoplasty for microbial keratitis in Taiwan from 1987 to 2001. Am J Ophthalmol. 2004;137(4):736-43.

9. Ramachandran L, Janakiraman D, Sharma S, Rao GN. Effect of time and washing on the adhesion of Acanthamoeba to extended wear disposable hydrogel contact lenses. CLAO J. 1997;23(2):113-6.

10. Lema I, Rodrígues-Ares MT, Gómez-Torreiro M, Peñalver MD. Adherence of Acanthamoeba to unworn conventional and disposable soft contact lenses. Cornea. 2001;20(6):635-8. 